\title{
Estudo das patologias da ponte sobre o Rio Tocantins em Porto Nacional/TO
}

As pontes são destinadas para transpor um obstáculo natural como córrego, vale, rios e etc.. Estão sujeitas a ações que provocam o aparecimento de deformações nas estruturas e assim, é preciso manutenção para manter o estado atual da obra. Ademais, a ausência de manutenção reduz a vida útil das Obras de Arte Especiais (OAE's) e na maioria dos casos acontece o abandono da estrutura. Nesse contexto, este trabalho tem como objetivo detectar as anomalias na Ponte sobre o rio Tocantins de Porto Nacional, situada na TO - 255 através de inspeção visual e registros fotográficos com o uso de VANT (Veículo Aéreo Não Tripulado). As inspeçõe seguiram as diretrizes da NBR 9452 (2016) e o manual de inspeção de Pontes Rodoviárias (DNIT, 2004). Por fim, verificou-se que a ponte, segundo o critério de classificação de condição de obras de artes especiais da NBR 9452 (2016), apresenta uma condição crítica, o que torna necessário uma imediata intervenção.

Palavras-chave: Patologia; Pontes; VANT.

\section{Study of the pathologies of the Tocantins River bridge in Porto Nacional/TO}

Bridges are meant to cross a natural obstacle like stream, valley, rivers and etc. They are subject to actions that cause the appearance of deformations in the structures and thus, maintenance is required to maintain the current state of the work. In addition, the lack of maintenance reduces the useful life of Special Artworks (OAEs) and in most cases the structure is abandoned. In this context, this work has as its main objective. This work aims to detect the anomalies in the Tocantins Bridge over Porto Nacional, located at TO - 255 through visual inspection and photographic records using UAV (Unmanned Aerial Vehicle). The inspections followed the guidelines of NBR 9452 (2016) and the Road Bridges Inspection Manual (DNIT, 2004). Finally, it was found that the bridge, according to the condition classification criterion of special art works of NBR 9452 (2016), presents a critical condition, which requires immediate intervention.

Keywords: Pathology; Bridges; UAV.

Topic: Engenharia Civil

Reviewed anonymously in the process of blind peer.
Received: 02/11/2019

Approved: 20/12/2019

Taluane Gomes da Silva (iD

Instituto Tocantinense Presidente Antônio Carlos, Brasil http://lattes.cnpq.br/2111244592170164

http://orcid.org/0000-0003-1287-287X

taluanesoares@hotmail.com

Douglas Freitas Augusto dos Santos

Instituto Tocantinense Presidente Antônio Carlos, Brasil

http://lattes.cnpq.br/6181125172616043

http://orcid.org/0000-0001-9306-5660

eng.prof.santos@gmail.com

Referencing this:

SILVA, T. G.; SANTOS, D. F. A.. Estudo das patologias da ponte sobre o Rio Tocantins em Porto Nacional/TO. Technology Science, v.2, n.1, p.33-36, 2020. DOI: http://doi.org/10.6008/CBPC26746425.2020.001.0006

DOI: 10.6008/CBPC2674-6425.2020.001.0006 


\section{INTRODUÇÃO}

As pontes são de grande importância para o desenvolvimento das distintas regiões, pois a estrutura tem por finalidade a transposição de um obstáculo natural como rio, mar, lago etc.. Ademais, é preciso fazer manutenção que é atividade destinada para manter o estado atual da obra e a sua ausência reduz a vida útil, tornando a ponte deficiente por razões estruturais. Logo, seguindo a necessidade de restauração, reforço ou substituição da obra.

Tendo em vista tal fato, o uso de VANT (Veículo Aéreo Não Tripulado) para captação de imagens possui grande potencial de técnicas e procedimentos tecnológicos atuais que permite agilidade e auxilia bastante na deteç̧ão de manifestações patológicas como, fissuras, manchas, deslocamentos, exposição das armaduras e etc..

Desta forma, este trabalho tem por objetivo identificar as manifestações patológicas presentes na ponte sobre o Rio Tocantins, mediante inspeção visual e registros fotográficos com o uso de Veículo Aéreo Não Tripulado seguindo as diretrizes da NBR 9452 (ABNT, 2016) e o manual de inspeção de Pontes Rodoviárias (DNIT, 2004).

\section{METODOLOGIA}

A pesquisa foi realizada na ponte (Obra de Arte Especial) sobre o Rio Tocantins, em Porto Nacional/TO, construída na década de 70 e localizada na TO-255 (Figura 1) que faz a ligação de Porto Nacional a Pinheirópolis. Para a realização de inspeção visual, foram feitas diversas visitas in loco com o uso da tecnologia de um veículo aéreo não tripulado (VANT), modelo DJI Mavic Pro (figura 2), para a captura de imagens aéreas.

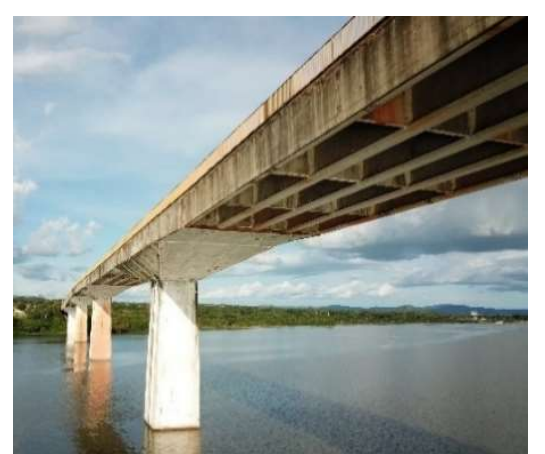

Figura 1: Ponte de Porto Nacional.

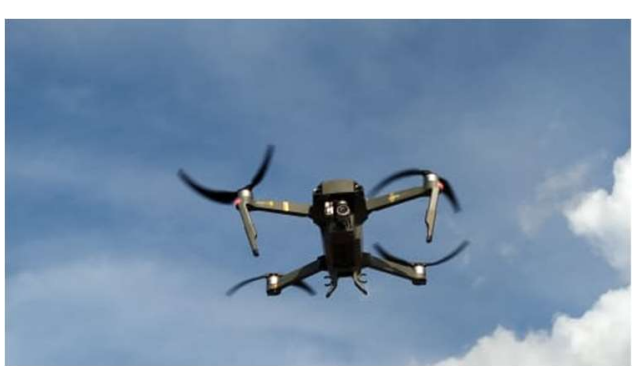

Figura 2: Drone DJI Mavic Pro.

\section{RESULTADOS E DISCUSSÃO}

Após a realização da inspeção visual da ponte através de registros fotográficos de visita in loco e uso do VANT foram verificados diversas manifestações patológicas, tais como fissura de cisalhamento, reação álcali-agregado, entre outras. Foi localizado um deslocamento de $8 \mathrm{~cm}$ do dente gerber, conforme ilustrado na Figura 3a. No encontro do dente gerber se observa uma fissura de cisalhamento extremamente crítica 
(Figura 3b). A fissura muitas vezes está relacionada com a falta de manutenção e/ou aumento das cargas móveis.

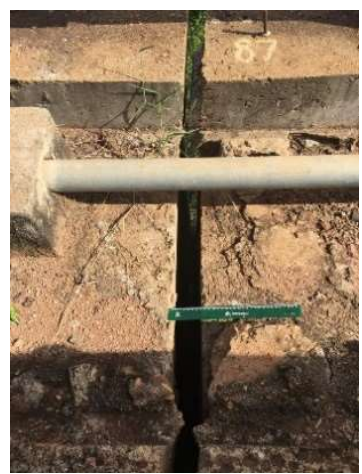

(a)

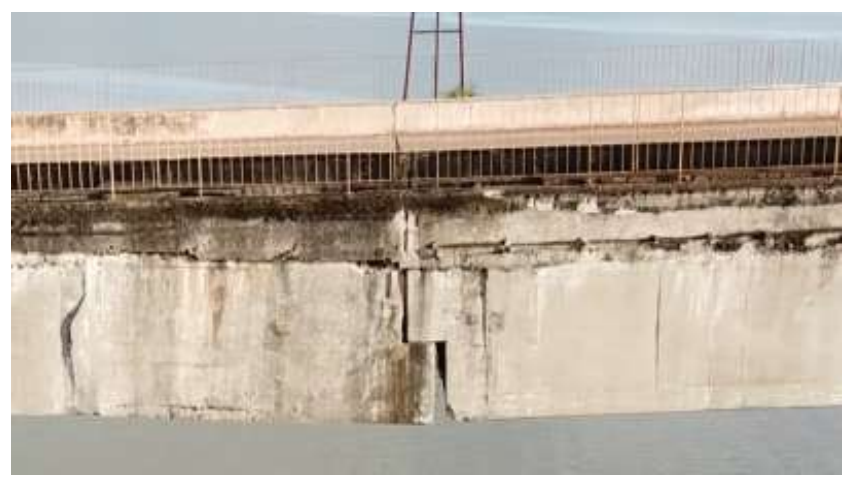

(b)

Figura 3: Deslocamento e fissuras de cisalhamento no dente gerber.

Foram observadas trincas e fissuras em praticamente toda a estrutura da ponte; essas fissuras podem ocorrer em consequência da fragilidade do concreto que continuamente está relacionado a fatores ambientais, por este motivo o concreto recebe uma tensão superior a tensão de tração que ele suporta motivando o aparecimento de fissuras na estrutura, chegando ao estado de fadiga (Figura 4). Além disso, nos pilares pode ser observado reação álcali agregado, através das fissuras na superfície provocadas pela reação dos componentes dos agregados do concreto com os álcalis do cimento (Figura 5). A reação álcali agregado é provocada pela expansão e fissuração no concreto por meio da reação química entre carbonatos e sílicas presentes nos agregados que compõem o concreto com os álcalis do cimento Portland.

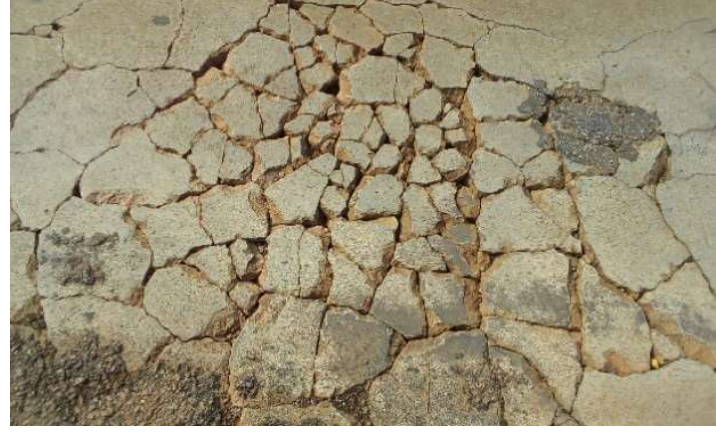

Figura 4: Fissuras e trincas.

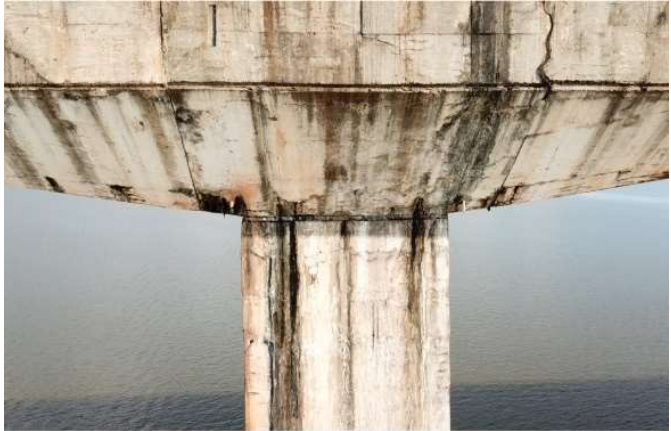

Figura 5: Reação álcali-agregado.

Outro fator observado na estrutura foi a exposição das armaduras; o mesmo está relacionado com as fissuras, ocorrendo penetração de água da chuva que causa a, dilatação, carbonatação e corrosão nas armaduras influenciando no desplacamento do concreto. As armaduras das estruturas de concreto armado estão protegidas pelo cobrimento, que é um impedimento físico contra esses agentes externos e ação química que causa sua deterioração, proporcionada pela alcalinidade presente no concreto, e assim, podemos ver que houve desplacamento do cobrimento (Figura 6).

Com a falta de manutenção houve o desgaste da placa de neoprene no dente gerber. E é necessário o uso de placas de neoprene para evitar o atrito entre os tabuleiros, com isso, é necessário que haja uma reposição dessas placas, quando isso não acontece ocorrem grandes impactos devido às cargas cíclicas e 
devido essas cargas em pontes serem cíclicas pode ocorrer a ruptura por fadiga. Dessa forma, houve deslocamento dos tabuleiros no dente gerber (Figura 6).

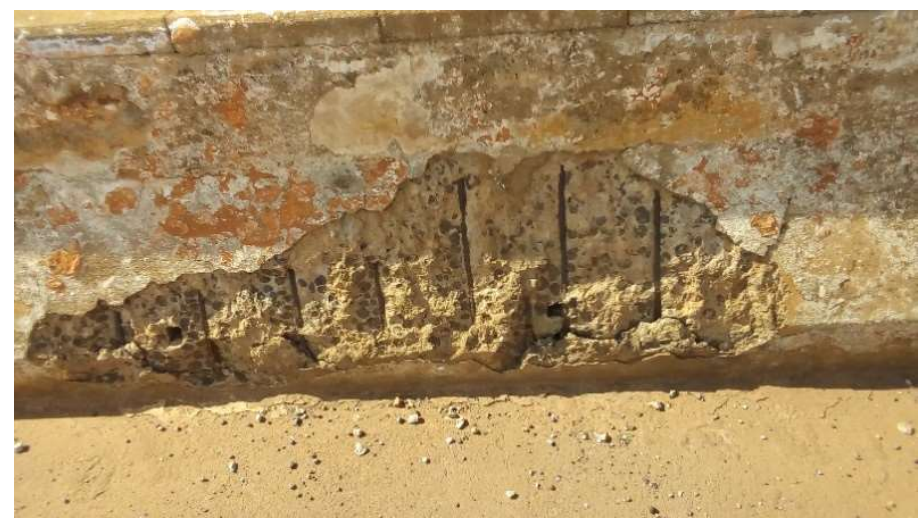

Figura 5: Perda de cobrimento e exposição da armadura.

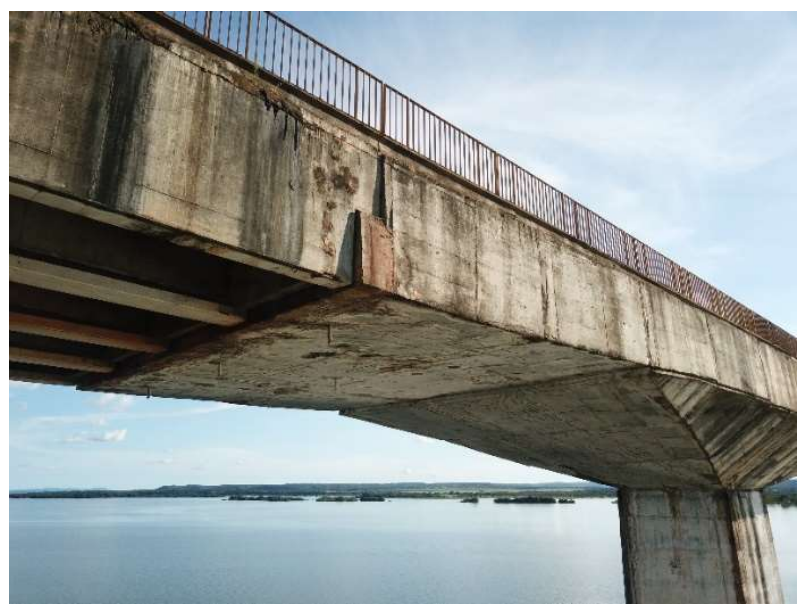

Figura 6: Dente Gerber.

\section{CONCLUSÕES}

A utilização de drones provou-se muito eficiente em se tratando de inspeções visuais em grandes estruturas como é caso das pontes, este fato se deve principalmente a possibilidade de acesso a diferentes locais de forma rápida e segura proporcionando uma análise prévia, que pode ser bastante útil em inspeções rotineiras.

A estrutura vistoriada, em geral, apresenta condições físicas preocupantes. Ela apresenta falhas de manutenção, devido a não intervenção preventiva e corretiva, que combateria os efeitos deletérios da ação dos fenômenos da natureza e das condições de uso. Bem como a não manutenção das juntas de dilatação de forma que as mantivesse em condições adequadas de trabalho.

\section{REFERÊNCIAS}

ABNT. Associação Brasileira de Normas Técnicas. NBR 9452: Inspeção de pontes, viadutos e passarelas de concreto Procedimento. Rio de Janeiro: ABNT, 2016.
DNIT. Departamento Nacional de Infraestrutura de Transportes. Manual de inspeção de pontes rodoviárias. 2 ed. Rio de Janeiro: DNIT, 2004. 